\title{
Detrimental effects of perfumes, aroma \& cosmetics
}

\begin{abstract}
Perfumes have been historically used primarily for fragrance. Aroma or fragrance has also been added to the cosmetics to make it more attractive. These fragrance products emit a range of chemicals including hazardous pollutants but the ingredients do not fully disclosed on the product label. Hence, they are found to cause various detrimental effects ion human health. The detrimental effects associated with the use of perfumes are contact dermatitis, contact urticaria, and photo allergy and photo toxicity. Detrimental effects of cosmetics are lungs disease, damage to reproductive organs, skin allergies, excessive hair problems, headache and cancer. The present review summarizes some of the harmful effects caused by the use of fragrance products including perfumes, aroma and cosmetics. Moreover, the preventive measures which have to be taken care of have also been discussed.
\end{abstract}

Volume 4 Issue 2 - 2020

\section{Mohammad Athar}

Department of Forensic Science, Institute of Excellence in

Higher Education, India

Correspondence: Mohammad Athar, Department of Forensic Science. Institute of Excellence in Higher Education, India, Email athar.fs148@gmail.com

Received: April 16, 2020 | Published: April 30, 2020

Keywords: detrimental, perfumes, contact dermatitis, photoallergy, antiperspirants

\section{Introduction}

The word perfume derives from the Latin perfumare, meaning "to smoke through". Perfumery, as the art of making perfumes, began in ancient Mesopotamia and Egypt and was further refined by the Romans and Persians. Fragrances are complex combinations of natural and/or man-made substances that are added to many consumer products to give them a distinctive smell. Fragrances are used in a wide variety of products to impart a pleasant odor, mask the inherent smell of some ingredients, and enhance the experience of using the product. It creates important benefits that are ubiquitous, tangible, and valued. They solve important functional problems and they satisfy valued emotional needs. Fragrances or aroma can communicate complex ideas creating mood, signalling cleanliness, freshness, or softness, alleviating stress, creating well-being, and triggering allure and attraction. ${ }^{1,2}$

The science of perfume and fragrance in cosmetics has advanced significantly over the years from the original isolation of ingredients from plant and animal sources to a sophisticated science that allows the preparation of unique new materials and sensitive methods for controlling both the composition and quality of fragrances. Creating a fragrance combines the art of perfumery with the extremely complex science of fragrance chemistry. Fragrance chemistry, a highly specialized fled, requires knowledge of the various substances and how these substances interact to produce the perceived odour. Additionally, many other factors have to be considered when formulating a fragrance including the strength of the smell, compatibility of ingredients with each other, the stability to light and heat, and even their interaction with product packaging. Also, it is important to consider the properties of the ingredients after they are applied to the skin. Some fragrance ingredients evaporate very rapidly, while others remain on the skin for longer periods of time. The interplay of these properties over time is very important in achieving the desired final effect that yields an aesthetically pleasing product. $^{3}$

But over exposure to these fragrance products can cause a range of adverse effects on human health including migraine headaches, contact dermatitis, asthma attacks, respiratory difficulties etc. The present review focuses on the occurrence of exposure to fragranced products and associated health and societal effects in human beings. Furthermore, some preventive measures have also been discussed in the present study.

\section{Detrimental effects of perfumes and/or aroma}

Exposure of perfumes aroma canceled out a variety of reaction which include contact dermatis, urticaria (hives), photoallergy and skin discolouration (dyschromia). It is believed that about $11-3 \%$ of allergic contact dermitis or allergic contact urticara caused by fragrances. women seem to be more often allergic to fragrances than men, reflecting a more frequent use of scented products among women. Perfumes most often cause skin allergy to fragrances $n$ women related products for men after-shave and deodorants. ${ }^{4,5}$

Furthermore, skin connecting intake of fragrance can truant or antagonise asthma and other respiratory disease. People with asthma, allergies, sinus problems and rhinitis are more responsive to immune trigger, and consistently at lower concentration than which determine problems $\mathrm{n}$ the common citizens. It rolled out to cause detrimental effects although the substance the movement are considered to be dangerous (decisive response). ${ }^{6-8}$ Some of the detrimental effects are:

Contact Dermatitis: Contact dermatitis is a type of skin rash. It occurs when skin comes into contact with chemicals or physical substances that cause an allergic or irritant reaction. Contact dermatitis can occur from exposure to many different compounds found both in the home and at work. There are 2 types of contact dermatitis:

Allergic contact dermatitis. This occurs when skin, which has become sensitive to a certain substance (allergen), comes in contact with that substance again. This is a delayed skin reaction that typically develops 12 to 72 hours after exposure.

Irritant contact dermatitis. This occurs when the skin is repeatedly exposed to a mild irritant (such as detergent or solvents) over a long period of time. If skin is exposed to a strong irritant (such as acid, alkali, solvent, strong soap, or detergent), skin damage can be immediate. $^{9}$ 
Antagonism Urticaria: Urticaria is a common dermatologic condition that typically presents with intensely pruritic, well-circumscribed, raised wheals ranging from several millimeters to several centimeters or larger in size. Urticaria can occur with angioedema, which is localized nonpitting edema of the subcutaneous or interstitial tissue that may be painful and warm. The intense pruritus can cause significant impairment in daily functioning and disrupt sleep. Typically otherwise benign and self-limited, urticaria can be a symptom of life-threatening anaphylaxis or, rarely, indicate significant underlying disease.

Phototoxicity and photoallergy: Phototoxic reactions occur because of the damaging effects of light-activated cell membrane compounds and DNA. These reactions are more common in individuals exposed to sufficient amounts of light and an exogenous agent, and usually appear as an exaggerated sunburn response. Phototoxic effects from direct tissue damaged caused by a photo-active compound. These compounds have the potential to cause photo-toxicity and have at least one resonating double bond or an aromatic ring that can absorb radiation energy. The most common causative agents are furocoumarins, acridinic dye or eosine, some drugs are more phototoxic, for example phenothiazines, tetracycilnes, sulfonamids and aminodarcone etc.

Photo allergic reactions are significantly less common than phototoxic reaction, still with unknown frequency. Men are more likely to have photo allergic effects than women, generally drugs induced photosensitivity reaction can occur in persons of any age. The carcinogenic potential due to prolonged exposure to photosensitizing drugs has been suggested. ${ }^{10,11}$

\section{Detrimental effects of cosmetics}

Cancer: The most threatening side effects of excessive use of cosmetics are skin cancer. Lipstick contains aluminum which may cause long term anemia and even glucose intolerance. Many products contain chemicals like zinc oxide and barium sulphate which are toxic and can result in organ failure, especially that of the kidney and liver. Cosmetics like body moisturizers can disturb the thyroid content of the body. Parabens, a preservative used heavily in cosmetics has been linked in researches to causes of cancer.

Damage to reproductive organs: Certain cosmetics such as bubble baths or oils can affect your reproductive organs and even lead to infertility. Talcum powder, if inhaled can travel to your reproductive system and can affect the menstrual cycles leading to other imbalances. Chemicals such a phthalates and parabens, used widely in cosmetics can disrupt reproductive hormones and hold potential risks to reproductive and thyroid systems. Cosmetics such as shower gels can lead to vaginal infections or even prostrate and ovarian cancer if brought in direct contact to your organs and if they are of a bad quality.

Lungs disease: The chemicals that are used in cosmetics are often breathed in, especially from fragrances or powders and they could lead to damaging of the lung tissues. Heavy makeup often triggers conditions of the lungs if inhaled. The chemical ingredients in talcum powder, such as silicates talc causes allergies and infections of the lungs. Powder based cosmetics are breathed in and can settled inside our lung tissues, they can also travel through our reproductive systems, causing undoable damages.

Facial stinging: There is a group of patients who note stinging or burning within several minutes after applying a cosmetic that intensifies over 5 to 10 minutes and then resolves after 15 minutes. This effect occurs without the patient exhibiting allergic contact dermatitis or irritant contact dermatitis with the applied substance. Tests should be done on the skin of the patient before using such components. Usually, substances such as benzene, phenol, salicylic acid, resorcinol and phosphoric acid are the main cause of facial stinging.

Excessive hair problems: Hair dressers often come into contact with various chemical substances which can be found in hair care products for washing, dyeing, bleaching, styling, spraying and perming. This exposure can impair health and may be present as skin and respiratory diseases.

Even if people don't use makeup, hair products are extensively used because hair is that aspect of your appearance which completes your look. Shampoos, conditioners, gels and serums may make your hair look perfect for the day, but in the long run they are doing nothing but damage to your hair. Such cosmetics affect the hair quantity and quality, causing hair fall, excessive dandruff, thinning of hair or redness of scalp. Hairsprays are even more dangerous as they can result in scalp damage and permanent discoloration of hair. Hair colors and hair dyes are next to toxic as allergic reactions can cause burning, redness, itchy scalp, breathing difficulties and facial swelling. The chemicals in hair dyes are toxic and can cause diseases like cancer, reproductive failure, and damage to lungs and so on. ${ }^{12,13}$

Headache: Headache is common issue associate with cosmetics usually prolong exposure to extensive makeup lead to dizziness, tiredness and nausea. The facts that contain only chemicals and some have certain ingredients that if exposed too directly, could lead to bouts of unconsciousness. It is probably more harmful for people who suffer migraines and chronic headache.

Redness: The redness of the skin caused by cosmetic products, especially soaps, is associated with the unbalance in cutaneous $\mathrm{pH}$. Modern soap is a blend of tallow and nut oil, or the fatty acids derived from these products, in a ratio of $4: 1$. This fact allows the $\mathrm{pH}$ of these soaps to be commonly alkalized ( $\mathrm{pH} 9-10)$, which can generate redness in the skin, which normally has a $\mathrm{pH}$ of 5.2-5.4. Ideally, such compounds should have neutral or slightly acidified $\mathrm{pH}$. Reason redness can occur is the use of moisturizers with a greater oily proportion, allowing skin warming throughout the day. ${ }^{14}$

\section{Studies that support the detrimental effects of cosmetics}

The scientific literature reveals that high amounts of chemical preservatives, perfumes and emulsifiers used in the manufacture of cosmetic products increase side effects and health risks through chemical and physical principles. ${ }^{15}$

Chemically, preservative compounds generally have chemical structures associated with aromatic rings which generally have toxic potential, and ability to bind to metal elements that promote bioaccumulation in the body. Although not all compounds that present toxic potential have their toxicity mechanism clarified in the literature, clinical evidence obtained by the side effects after the use of these substances point to the health risk associated with the use of cosmetics. The health risk associated with the use of cosmetics can range from a simple mild hypersensitivity reaction to an anaphylactic process or even a lethal intoxication. ${ }^{16}$ Cancer is also a complication associated with the use of cosmetics in the face of clinical evidence reported in the literature. 
Faced with the occurrence of side effects, the imminence of complications associated with the use of cosmetics contribute to an emerging public health problem, it is concluded that the process of quality control in the manufacture of cosmetic products is not completely effective in preventing health risks associated with the use of cosmetic products..$^{14,17,18}$

\section{Preventive measures to reduce problems associated with perfumes, aroma and cosmetics:}

It is impossible to predict whether you will get a detrimental effect from a product, but you can take some steps to reduce potential problems:

- Check the expiry date. Some products are not labelled with a use-by date but are marked with the time the product is usable after opening. Do not use products where the expiry date or duration time have expired

- Use cosmetic products as indicated. For example, do not use hair products intended for hair on eyebrows or eyelashes

- Avoid products that contain substances you are allergic to

- Stop using a product if you suspect that it is causing adverse effects

\section{- Contact your doctor if severe adverse effects persist ${ }^{19}$}

To encourage improvements in the manufacture, marketing and use of cosmetic products by the population, it is necessary to apply a unified cosmetovigilance around the world. This public health strategy are a genuine means of obtaining information on the safety of cosmetic products and their ingredients, preventing the risks associated with using cosmetics become a serious public health problem. ${ }^{20}$

\section{Conclusion}

Fragrance products such as perfumes, and other cosmetics emit and generate a complex mixture of chemicals, ncluding hazardous carcinogenic pollutants. There $\mathrm{s}$ direct exposure of ingredients of fragrance products to skin, nose, eyes, mouth, and respiratory system, which may cause serious aesthetic problems. The problem of fragranced products is sweeping all over the world, resulting in adverse health effects, lost workdays, and inability to access public places, such as restrooms and businesses. Fragrance ingredients in cosmetics must meet the same requirement for safety as other cosmetic ingredients. They must be safe for consumers when they are used according to labeled directions, or as people customarily use them. This is a responsibility that fragrance manufacturers and the companies that use fragrances in their products take very seriously. While further research is needed to better understand which chemicals and mixtures are associated with the effects, what is known is that the products are reportedly causing adverse effects in a sizeable (33\%) percentage of the population. Further, the effects can be immediate, severe, and potentially disabling.

\section{Conflicts of interest}

There is no conflict of interest

\section{Acknowledgments}

None.

\section{Funding}

None.

\section{References}

1. Breithaupt A, Jacob SE. Thiomersal and the relevance of patch-test reactions in children. Dermatitis. 2008;19:275-277.

2. Draelos ZD.Facial skin care products and cosmetics. Clin Dermatol. 2014;32(6):809-812.

3. Lintner K, Genet V. A physical method for preservation of cosmetic products. Int J Cosmet Sci. 1998; 20(2):103-15.

4. Yim E, Baquerizo Nole KL, Tosti A. Contact dermatitis caused by preservatives. Dermat. 2014;25(5):215-231.

5. Hendriks S, Ginkel C. Evaluation of the fragrance mix in the European Standard Series. Contact Dermatitis. 2000;41:161-164.

6. Elberling J, Linneberg A, Dirksen A, et al. Mucosal symptoms elicited by fragrance products $\mathrm{n}$ a population-based sample $\mathrm{n}$ relation to atopy and bronchial hyper-reactivity. Clin. Exp. Allergy. 2005; 35(1):75-81.

7. Kumar P, Caradonna-Graham VM, Gupta S, et al. Inhalation challenge effects of perfume scent strips n patients with asthma. Ann. Allergy Asthma mmunol. 1995;75(5):429-433.

8. Johansen JD. Fragrance contact allergy: a clinical review. Am J Clin Dermatol. 2003;4(11):789-798.

9. Klimańska M, Żmudzińska M, Jenerowicz D, et al. The importance of exposure to contact allergens in patients with allergic contact dermatitis. Postep Derm Alergol. 2011;28:203-211.

10. Kiec-Świerczyńska M, Kręcisz B, Świerczynska-Machura D. Contact allergy to fragrances [Polish]. Med Prakt. 2006;57:431-437.

11. Kiec-Świerczyńska M, Kręcisz B, Świerczyńska-Machura D. Contact allergy to para-(amino) compounds in European Standard Series [Polish] Przegl Dermatol. 2008;3:287-292.

12. Zhang Y, Kim C, Zheng T. Hair dye use and risk of human cancer. Front Biosci (Elite Ed). 2012; 4:516-528.

13. Krasteva M, Cristaudo A, Hall B, et al. Contact sensitivity to hair dyes. Eur J Dermatol. 2002;12:322-325.

14. Hałat Z. Adverse reactions to cosmetics. Alergia. 2003:36-40.

15. Steinemann AC, Mac Gregor C, Gordon SM, et al. Fragranced consumer products: chemicals emitted, ngredients unlisted. Environ mpact Assess Rev. 2011;31(3):328-333.

16. Miller CS, Prihoda TJ. The environmental exposure and sensitivity nventory (EESI): a standardized approach for measuring chemical ntolerances for research and clinical applications. Toxicol nd Health. 1999;15(34):370-385.

17. Heydorn S, Johansen JD, Andersen KE, et al. Fragrance allergy in patients with hand eczema - a clinical study. Contact Dermatitis. 2003;48:317323.

18. Johansen J, Menne T. The fragrance mix and its constituents: a 14-year material. Contact Dermatitis. 1995;32:15-23.

19. Kręcisz B. Photodermatoses. In: Kieć-Świerczyńska M, editor. Principles of diagnosis, case law and the prevention of occupational diseases of the skin Warsaw. Postgraduate Medical Education Center. 2010. p. 85-93.

20. Larsen WG. How to test for fragrance allergy. Cutis. 2000;65:39-41. 